\title{
Effect of seating forces on cement-ceramic adhesion in microtensile bond tests
}

Marocho, Susana María Salazar ; Ȯzcan, Mutlu ; Amaral, Regina ; Valandro, Luiz Felipe ; Bottino, Marco Antonio

\begin{abstract}
OBJECTIVES: The aim of this study was to evaluate the effect of different seating forces during cementation in cement-ceramic microtensile bond strength ( $\mu$ TBS). MATERIALS AND METHODS: Forty-five blocks ( 5 $\times 5 \times 4 \mathrm{~mm}(3))$ of a glass-infiltrated alumina-based ceramic (In-Ceram Alumina) were fabricated according to the manufacturer's instructions and duplicated in resin composite. Ceramic surfaces were polished, cleaned for 10 min in an ultrasonic bath, silica coated using a laboratory type of air abrasion device, and silanized. Each treated ceramic block was then randomly assigned to five groups $(n=9)$ and cemented to a composite block under five seating forces $(10 \mathrm{~g}, 50 \mathrm{~g}, 100 \mathrm{~g}, 500 \mathrm{~g}$, and $750 \mathrm{~g})$ using a dual-cured resin cement (Panavia F). The ceramiccement-composite assemblies were cut under coolant water to obtain bar specimens $(1 \mathrm{~mm} \times 0.8 \mathrm{~mm}(2))$. The $\mu$ TBS tests were performed in a universal testing machine $(1 \mathrm{~mm} / \mathrm{min})$. The mean bond strengths values were statistically analyzed using one-way ANOVA $(\alpha \leq 0.05)$. RESULTS: Different seating forces resulted in no significant difference in the $\mu$ TBS results ranging between $13.1 \pm 4.7$ and $18.8 \pm 2.1 \mathrm{MPa}(\mathrm{p}=0.13)$ and no significant differences among cement thickness. CONCLUSIONS: Excessive seating forces during cementation seem not to affect the $\mu$ TBS results. CLINICAL RELEVANCE: Excessive forces during the seating of single all-ceramic restorations cementation seem to display the same tensile bond strength to the resin cement.
\end{abstract}

DOI: https://doi.org/10.1007/s00784-011-0668-y

Posted at the Zurich Open Repository and Archive, University of Zurich

ZORA URL: https://doi.org/10.5167/uzh-75643

Journal Article

Accepted Version

Originally published at:

Marocho, Susana María Salazar; Ȯzcan, Mutlu; Amaral, Regina; Valandro, Luiz Felipe; Bottino, Marco Antonio (2013). Effect of seating forces on cement-ceramic adhesion in microtensile bond tests. Clinical Oral Investigations, 17(1):325-331.

DOI: https://doi.org/10.1007/s00784-011-0668-y 
Effect of seating forces on cement-ceramic adhesion in microtensile bond tests

Susana María Salazar Marochoa, Mutlu Özcan ${ }^{\mathrm{b}}$, Regina Amaral ${ }^{\mathrm{a}}$, Luiz Felipe Valandro $^{c}$, Marco Antonio Bottino ${ }^{d}$

${ }^{a}$ DDS, MS. São Paulo State University, Department of Dental Materials and Prosthodontics, SÃO PAULO STATE UNIVERSITY - UNESP, Brazil

${ }^{b}$ DMD, PhD, Professor University of Zürich, Head of Dental Materials Unit, Center for Dental and Oral Medicine, Clinic for Fixed and Removable Prosthodontics and Dental Materials Science.

${ }^{\mathrm{c}}$ DDS, MS, PhD. Professor - Federal University of Santa Maria, Department of Restorative Dentistry, Brazil.

d DDS, MS, PhD. Professor - São Paulo State University, Department of Dental Materials and Prosthodontics, SÃO PAULO STATE UNIVERSITY - UNESP, Brazil

\section{Corresponding author:}

Susana María Salazar Marocho, DDS, MS (S. M. Salazar Marocho)

E-mail address: salazar.marocho@gmail.com

Phone number: +55-12-81438843; fax number: +55-12-39479010. 


\section{ABSTRACT}

Objectives. To evaluate the effect of different seating forces during cementation in cement-ceramic microtensile bond strength ( $\mu$ TBS). Materials and Methods. Forty five blocks $\left(5 \times 5 \times 4 \mathrm{~mm}^{3}\right)$ of a glass-infiltrated alumina-based ceramic (IA- In-Ceram Alumina) were fabricated according to the manufacturer's instructions and duplicated in resin composite. Ceramic surfaces were polished, cleaned for $10 \mathrm{~min}$ in an ultrasonic bath, silica coated using a laboratory type of air abrasion device and silanized. Each treated ceramic block was then randomly assigned to five groups $(n=9)$ and cemented to a composite block under 5 seating forces $(10 \mathrm{~g}, 50 \mathrm{~g}, 100 \mathrm{~g}$, $500 \mathrm{~g}$ and $750 \mathrm{~g}$ ) using a dual-cured resin cement (Panavia F). The ceramic-cementcomposite assemblies were cut under coolant water to obtain bar specimens $(1 \mathrm{~mm} x$ $\left.0.8 \mathrm{~mm}^{2}\right)$. The $\mu$ TBS tests were performed in a universal testing machine $(1 \mathrm{~mm} / \mathrm{min})$. The mean bond strengths values were statistically analyzed using one-way ANOVA $(\alpha \leq 0.05)$. Results. Different seating forces resulted in no significant difference in the $\mu$ TBS results ranging between $13.1 \pm 4.7$ and $18.8 \pm 2.1 \mathrm{MPa}(p=0.13)$ and no significant differences among cement thickness. Conclusions. Excessive seating forces during cementation seem not to affect the $\mu$ TBS results.

Clinical relevance. Excessive forces during the seating of single all-ceramic restorations cementation seem to display the same tensile bond strength to the resin cement.

KEYWORDS: Microtensile bond strength, Glass-infiltrated alumina-based ceramic, Seating forces, Cementation 


\section{INTRODUCTION}

To establish a durable and reliable bond between the ceramic restoration and the resin composite constitutes an important issue in the dental practice because of the widely use of clinicians of resin-bonded restorations.

Basically, this bond is usually created via two mechanisms, micro-mechanical attachment by hydrofluoric acid (HF) etching and/or gritblasting and chemical bonding by a silane coupling agent [1], depending on the microstructure of the ceramic chosen. Acid etchants used for silica-based dental ceramics do not sufficiently roughen the surface of aluminum-oxide ceramics [2]. The Rocatec system was first used as an option to condition ceramic surfaces with high alumina concentrations, as In-Ceram system; this system promotes silica coating on the ceramic surface, and allows bonding to silane agents and resin cements.

A durable resin bond to glass-infiltrated alumina ceramic was achieved with both, a combination of tribochemical silica coating and conventional bis-GMA composite resin or with a combination of sandblasting and composite resin modified with a phosphate monomer. These two bonding methods appeared suitable for clinical bonding of In-Ceram ceramic restorations [3-5].

Resin cements still necessitate compromises in clinical handling as a consequence of inherent material properties [6-7]. Resin composite cements contract during setting, which causes stresses in the thin adhesively bonded cement layer [810]. These stresses may exceed the cohesive or bond strengths placing restoration longevity at risk [11]. Also additional stresses in the cement, like stresses due to bite forces on the cemented restoration, will increase the probability of bonding failure. For that reason the design of the cement layer is important. However, further researches are needed to assess the stresses occurring in the clinical situation [12]. 
In fact, the first stress that a bonded-restoration goes through is during the cementation procedure, as the restoration is submitted to pressure when it is placed on the prepared tooth. Several studies have investigated different techniques for cementation in order to find an optimal technique for that procedure [13]. The authors studied the pressuring techniques and cement thickness in cast restorations, verifying that an optimal technique for cementation is to seat the casting by finger pressure and then apply horizontal vibration under hand pressure.

Moreover, Ken et al, 1996 [14] found that a thin layer of cement produces greater seating accuracy than a thick layer. Feilzer et al., 1989 [15] verified that when reaching a critical magnitude, the setting stress might even induce a premature debonding of certain areas in the adhesive joint. This generated polymerization stress might be even more significant in thin bonded resin layers due to unfavorable geometry, known as the configuration factor (C-factor). There are limited studies about the relevant seating force applied by clinicians during cementation, related to the bond strength of the ceramic restoration to the resin cement. Thus, the aim of this study was to evaluate whether different seating forces on ceramic blocks during cementation would influence on the microtensile bond strength of resin to a glassinfiltrated alumina ceramic and resin cement thickness.

\section{MATERIALS AND METHODS}

\section{Obtainment of ceramic and resin blocks}

Forty five ceramic blocks $\left(5 \times 5 \times 4 \mathrm{~mm}^{3}\right)$ of a glass-infiltrated alumina-based ceramic (In-Ceram Alumina VITA Zahnfabrik, Bad Sackingen, Germany) were fabricated according to the manufacturer's instructions. 
Ceramic surfaces were ground finished up to 1200-grit silicon carbide abrasive in a polishing machine (Labpol 8-12, Excet, USA) and cleaned in an ultrasonic bath (VITASONIC II, In-Ceram VITA, Zahnfabrik, Bad Sackingen, Germany) for 10 minutes.

Each ceramic block was duplicated in composite resin immediately before cementation (W3D-MASTER, Wilcos, Rio de Janeiro, Brazil) using a mold made out of poly(vinyl siloxane) impression material (Elite HD, Zhermack, Badia Polesine, Italy). The block was placed inside the silicone to get some space to build the composite blocks. Composite resin layers were incrementally condensed into the mold and light polymerized for 40s (XL 3000, 3M/ESPE, St. Paul, Minneapolis, USA) with a light intensity of $500 \mathrm{~mW} / \mathrm{cm}^{2}$.

The cementation surfaces of all ceramic blocks were silica coated using the CoJet system (CoJet, 3M-Espe, Seefeld, Germany), perpendicular to the surface at a distance of $10 \mathrm{~mm}$ for $20 \mathrm{~s}$, and at a pressure of 2.8 bars in circling movements. Then silane coupling agent (Monobond S - Ivoclar Vivadent, Schaan, Liechtenstein) was applied with a clean brush one layer, allowing enough time to evaporate.

\section{Specimen preparation - Cementation}

All ceramic blocks were divided into five groups $(n=7)$, according to the seating forces (gf) applied during cementation: $G_{10}$ (10gf), $G_{50}(50 g f), G_{100}(100 g f), G_{500}$ (500gf) and $G_{750}$ (750gf), which were maintained throughout the entire photo polymerization period of the resin cement. The resin cement (Panavia F, Kuraray CO., Okayama, Japan) was mixed following the manufacturer's instructions (Table 1), placed on the treated ceramic surfaces and, luted to the corresponding resin composite block under the seating forces mentioned above. During this period, the excess resin cement was removed and light polymerized (XL 3000, 3M ESPE, MN, 
USA) uniformly, for $40 \mathrm{~s}$ on each side of the specimen. Oxyguard was applied around the resin cement layer to ensure complete anaerobic polymerization. Next, the blocks were washed with air-water spray and stored in distilled water at $37^{\circ} \mathrm{C}$ for $24 \mathrm{~h}$ prior until preparation of the specimens to bond tests.

Then, the microtensile bond strength test was performed following a technique previously described by Amaral et al. [16]. The blocks were bonded with cyanoacrylate glue (Super Bonder Gel, Loctite Ltd, São Paulo, Brazil) to a metal base that was coupled to a cutting machine. The blocks were positioned perpendicular to the diamond disk (Microdont, São Paulo, Brazil) under water cooling to produce five slices per assembly. Each slice was approximately $1 \mathrm{~mm}$ thick and was then rotated in $90^{\circ}$ and once again glued with cyanoacrylate to the metallic base. The peripheral slices were disregarded so that the results would not be influenced by either the excess or the insufficient amount of resin cement at the interface. Subsequently, a maximum of nine sections per assembly were achieved, also measuring $0.8 \pm 0.1 \mathrm{~mm}$ in thickness. The cross-section surfaces were measured with digital micrometer.

\section{Microtensile bond strength test}

Each beam specimen was glued with cyanoacrylate parallel to the long axis of an adapted caliper keeping the adhesive zone free in order to minimize the tensile forces. The caliper was coupled to the universal testing machine (EMIC DL-1000, São José dos Pinhais, Brazil) as parallel as possible in relation to application of the tensile load, and the specimens were loaded in tension to failure at a crosshead speed of $1 \mathrm{~mm} \mathrm{~min}^{-1}$. 
Interfacial bond strength values were expressed in MPa using a mathematical formula $R=F / A$, where $R$ is the strength (MPa), $F$ is the load required for rupture of the specimen $(N)$ and $A$ is the interface area of the specimen $\left(\mathrm{mm}^{2}\right)$.

All specimens submitted to the microtensile bond strength test were analyzed under optical microscope (Mitutoyo, São Paulo, Brazil), and some specimens were selected for analysis under scanning electron microscope (SEM) at 1000x magnification for observation of the type of failures and measurement of the thickness of the resin cement layers. Types of failures were classified as ADHES failure between ceramic and cement; MIX - cohesive failure of cement and ceramic; COHES-cem - cohesive failure of the cement; and COHES-cer - cohesive failure of ceramic.

\section{Statistical analysis}

Statistical analysis was performed using software Statistics 8.0 for Windows (Analytical Software Inc, Tallahassee, FL, USA). Bond strength data (MPa) were analyzed by one-way analysis of variance (ANOVA, $\alpha=0.05$ ).

\section{RESULTS}

Mean and standard deviations of the microtensile bond strength values (MPa) are shown in Figure 1.

One-way ANOVA revealed no significant influence of the seating forces $(p=0.13)$ applied for cementation on the microtensile bond strength values. Table 2 presents the number of tested specimens per group and type of failure after the microtensile bond strength test.

Also, the effect of seating pressure was examined by comparing the thickness of resin cement layer formed after the application of different forces in the 
cementation procedures of all the experimental groups. When applied seating forces

between $10 \mathrm{gf}$ and $500 \mathrm{gf}$ the cement thickness did not showed any statistically significant difference (Figure 2). 


\section{DISCUSSION}

The cementation protocol for all-ceramic restorations can be essential for clinical success. Thus, depending on the microstructure of the ceramic used to manufacture the dental restoration, it can effectively be treated for conventional or adhesive cementation, either with hydrofluoric acid etching, or airborne particle abrasion, and also using a silica coating technique. Together with those surface conditioning methods, silane application has been considered effective in the conditioning method for bonding resin composites to oxide ceramics [17].

Typically, in the cementation procedure a restoration is placed over the tooth and the patient applies biting pressure on an object to force the crown into place. Most of the time, patients applied biting pressure over an orangewood stick during the cementation of the restoration. However, the use of an orangewood stick may result in the cracking or chipping of the ceramic restoration, necessitating the time and expense of manufacturing and reseating a new restoration. Furthermore, the force applied to the crown with the use of the orangewood stick is uneven and can result in a restoration that is improperly seated.

Clinically the surface is very variable, depending on the region of the mouth and the design of the preparation cut [18], and these prior art devices(????) may fail and not allow for uniform loading of the central groove of the tooth to be crowned, without also loading the lingual or buccal cusps of the crown.

An early study [19] showed that it is recommendable to apply firm pressure down the long axis of the tooth preparation, with the index finger for 10 to 15 seconds. 
A wide range of cementation forces have been used in many studies in the cementation procedure of restorations, ranging from a minimum of $22.5 \mathrm{~N}$ [20] to a maximum of $700 \mathrm{~N}$ [21].

When a measurement system was used, and a load cell was mounted in a finger stall in order to measure the force applied during cementation, it was found that clinicians applied initially about $59 \mathrm{~N}$ for a few seconds, followed by a constant force of 20 to $30 \mathrm{~N}$ to metal crowns, and lower forces (26 N) to porcelain crowns [18]. In addition, the results found in a recent investigation [21], showed that the finger pressure applied by dentists varies and ranged from 12 to $67 \mathrm{~N}$, revealing a statistically significant difference with finger pressure applied during cementation.

However, from a biological point of view, in relation to pulp tissue reaction, it has been proven that forces used in the cementation procedure can generate intracoronal hydraulic pressure. This cementation pressure has been successfully measured in vitro $[23,24]$, suggesting that reduction of the seating force significantly reduced pressure transmitted to the pulp chamber, while the seating of the crowns worsened with reduced seating force. Moreover, when Humplink and Wilson [25] investigated oscillating seating force during cementation to a low seating force $(5 \mathrm{~N}=$ $509.9 \mathrm{gf})$, they found that oscillation of a crown during cementation improved postcementation seating but also increased pulpward pressure transmission. Hence, from the above-mentioned results, in this study the application of forces lower than $500 \mathrm{gf}$, and a higher force (750gf) were chosen to evaluate if they would influence the bond strength between a ceramic and a resin cement, mainly because those loads are applied while the dental cement sets and a bond between the crown and tooth is formed. 
In this study, the microtensile bond strength test was selected on account of the uniform pattern of stress. This test was indicated to be trustworthy to test how well one material bonds to another, hence, it is adequate to assess the quality of the adhesive bond of resin composite to ceramics. Also, it presents a less complex layout [26].

The experimental design of this study was planned to minimize any interfering variables related to the tooth structure. Flat ceramic surfaces were preferred instead of anatomical ceramic restorations because microtensile bond strength methodology was used. The fracture origin areas in those restorations were located where hoop stresses predominated, near the restoration margin [27] and that event may compromise bond strength results.

According to our results, the adverse effects of seating forces on pulpal health could probably be avoided, considering that $10,50,100,500$ and 750 gf seating forces had all no significant differences in their effect during the cementation in terms of bond strength. Notwithstanding this last statement, Jager [12] stated that stresses in the cement like stresses due to bite forces on the cemented restoration, will increase the probability of bonding failure.

Nevertheless, with such forces documented in different studies, it is not certain what constitutes a relevant force clinically, and which force level could affect the bond strength of the ceramic restoration to the resin cement.

Jorgensen [28] noted that as pressure was exerted on dental cement, filtration of cement constituents into a solid and a less viscous (most reactive) liquid phase occurs. Even though, the studies described above are not directly related to ours, it is important to assess the effect of seating forces over another possible implications. 
A recent investigation [29] indicated that sustained pressure application (1.25 $\mathrm{MPa}$ ) during the entire course of the setting of a dual-cured resin cement ( $3 \mathrm{~min})$ improves the bond strength and reduces fluid interference from the underlying dentin, with bonding covered dentin. Even though, the later study did not apply the same method with our study, since the substrate used in the current study was a resin composite material, and the complex ceramic-cement-resin was not submitted to any aging procedure; our results are in agreement with the fact that the application of sustained seating pressure during the curing of the resin cement has no influence on the microtensile bond strength between two structures. Also, it is shown that the surface conditioning method used in ceramic surfaces seems to be sufficient to ensure adequate bond strength for clinical use.

Some authors [30-31] suggested that cement thicknesses between 50-100 $\mu \mathrm{m}$ can be acceptable. Molin et al [31] found that bond strength values for Vita CEREC and Mirage specimens to dual-cured resin cement were significantly lower when used the thinnest cement layer $(20 \mu \mathrm{m})[31]$. As dental restorations are exposed to wet environment once placed in the oral cavity, changes in the dimensions of the resin cement due to water sorption occurred as the period of water contact became longer. However, in ideal conditions this is not expected to occur. Since fracture in ceramic inlays and crowns has been reported and attributed to the expansion of the resin cement $[32,33]$, thick cement layer might have a hazardous effect on allceramic restorations life. Moreover, Rekow et al. [34] found that thin cement layers (80-100 $\mu \mathrm{m})$ had low influence on maximum principle stress in the all-ceramic crown. Unquestionably the performance of the all-ceramic crown-cement-tooth supporting structure system is complex and interactions between variables can influence the maximum principal stress within a crown but this is rarely reported [34]. 
Altogether, due to the use of different resin cements in our study, comparing to the later ones, no exact comparison of the different bonding approaches could be carried out. Nevertheless, concerning resistance to compressive loading and bending stress, thin layer of resin cement seems to be less resistant compared to a thicker layer [31].

\section{CONCLUSIONS}

Within the limitations of this study, the results suggest that when the resin cement is submitted indirectly to low or high seating forces in the cementation procedure, the probability of bonding failure remains the same. Thus, seating forces in the range of 10 to $750 \mathrm{~g}$ may not influence in the tensile bond strength between the resin cement and the ceramic structure.

The authors declare that they have no conflict of interest. 


\section{REFERENCES}

1. Hooshmand T, van Noort R; Keshvad A (2002) Bond durability of the resinbonded and silane treated ceramic surface. Dent Mater 18:179-88

2. Awliya W, Oden A, Yaman P, Dennison JP, Razzoog ME (1998) Shear bond strength of a resin cemented to densely sintered high-purity alumina with various surface conditions. Acta Odontol Scand 56:9-13

3. Kern M, Thompson VP. Bonding to glass infiltrated alumina ceramic: adhesive methods and their durability (1995). J Prosthet Dent 73:240-9

4. Sadoun M, Asmussen E (1994) Bonding of resin cements to an aluminous ceramic: a new surface treatment. Dent Mater 10:185-9

5. Özcan M, Alkumuru HN, Gemalmaz D (2001) The effect of surface treatment on the shear bond strength of luting cement to a glass-infiltrated alumina ceramic. Int J Prosthodont 14:335-9

6. Van Meerbeek B, Inokoshi S, Willems G, Noack MJ, Braem M, Lambrechts P, Roulet JF, Vanherle G (1992) Marginal adaptation of four tooth-coloured inlay systems in vivo. J Dent 20:18-26

7. Hansen EK, Asmussen E (1993) Correlation between depth of cure and surface hardness of a light-activated resin. Scand J Dent Res 101:62-64

8. De Gee AJ, Feilzer AJ, Davidson CL (1993) True linear polymerization shrinkage of unfilled resins and composites determined with a linometer. Dent Mater 9:1114

9. Magne P, Versluis A, Douglas WH (1999) Effect of luting composite shrinkage and thermal loads on the stress distribution in porcelain laminate veneers. $\mathrm{J}$ Prosthet Dent 81:335-44 
10. Watts DC, Kisumbi BK, Toworfe GK (2000) Dimensional changes of resin/ionomer restoratives in aqueous and neutral media. Dent Mater 16:89-96

11. Geurtsen W. Crown and restoration margins (1990) Dtsch Zahnarztl Z 45:380-6

12. Jager N, Pallav P, Feilzer AJ (2005) Finite element analysis model to simulate the behavior of luting cements during setting. Dent Mater 21:1025-1032

13. Koyano E, Iwaku M, Fusayama T (1978) Pressuring techniques and cement thickness for cast restorations. J Prosthet Dent 40:544-8

14.Ken T, Ibbetson R (1996) The effect of cement volume on crown seating. Int J Prosthodont 9:445-51

15. Feilzer AJ, De Gee AJ, Davidson CL (1989) Increased wall-to-wall curing contraction in thin bonded resin layers. J Dent Res 68:48-50

16. Amaral R, Özcan M, Valandro L, Valducci I, Bottino MA (2008) Effect of conditioning methods on the microtensile bond strength of phosphate monomerbased cement on zirconia ceramic in dry and aged conditions. J Biomed Mater Res B Appl Biomater 85:1-9

17. Özcan M, Vallittu K (2003) Effect of surface conditioning methods on the bond strength of luting cement to ceramics. Dent Mater 19:725-31

18. Black S, Amoore JN (1993) Measurement of forces applied during the clinical cementation of dental crowns. Physiol Meas 14:387-92

19. Kuhl MA. A final cementation technique (1997) J Am Dent Assoc 128:1286

20.Wang C-J, Millstein PL, Nathanson D (1992) Effects of cement, cement space, marginal design, seating aid materials, and seating force on crown cementation. J Prosthet Dent 67:786-90

21. Moore JA, Barghi N, Brukl CE, Kaiser DA (1985) Marginal distortion of cast restorations induced by cementation. J Prosthet Dent 54:336-340 
22.Zortuk M, Bolpaca P, Kilic K, Ozdemir E, Aguloglu S (2010) Effects of Finger Pressure Applied By Dentists during Cementation of All- Ceramic Crowns. Eur J Dent 4:383-388

23. Wylie SG, Wilson PR (1994) An investigation into the pressure transmitted to the pulp chamber on crown cementation: a laboratory study. J Dent Res 73:1684-9

24. Wong RH, Wilson PR (1997) The effect of seating force and die spacing on pulpward cementation pressure transmission: a laboratory study. Int Dent $\mathrm{J}$ $47: 45-52$

25. Humplink AJ, Wilson PR (2001) The effect of oscillation and low seating force on pulpward pressure transmission and seating during crown cementation. A laboratory study. Int J Prosthodont 14:53-7

26. Della Bona A, van Noort R (1995) Shear vs. tensile bond strength of resin composite bonded to ceramic. J Dent Res 74:1591-6

27. Quinn JB, Quinn GD, Kelly JR, Scherrer SS (2005) Fractographic analyses of three ceramic whole crown restoration failures. Dent Mater 21:920-9

28. Jorgensen KD. Factors affecting the film thickness of zinc phospate cements (1960) Acta Odontologica Scandinavica 18:479-90

29. Chieffi N, Chersoni S, Papacchini F, Vano M, Goracci C, Davidson CL, Tay FR, Ferrari M (2007) The effect of application sustained seating pressure on adhesive luting procedure. Dent Mater 23:159-164

30. Kramer N, Frankenberger R (2000) Leucite-reinforced glass ceramic inlays after six years: wear of luting composites. Oper Dent 25:466-72

31. Molin MK, Karlsson SL, Kristiansen MS (1996) Influence of film thickness on joint bend strength of a ceramic/resin composite joint. Dent Mater 12:245-249 
32. Sindel J, Frankenberger R, Kramer N, Petschelt A (1999) Crack formation of all ceramic crowns dependent on different core build-up and luting materials. J Dent $27: 175-81$

33. Federlin M, Schmidt S, Hiller KA, Thonemann B, Schmaltz G (2004) Partial ceramic crowns: influence of preparation design and luting material on internal adaptation. Oper Dent 29:560-70

34. Rekow ED, Harsono M, Janal M, Thompson VP, Zhang G (2006) Factorial analysis of variables influencing stress in all-ceramic crowns. Dent Mater 22:12532

- The paper was presented at the $85^{\text {th }}$ IADR General Session, July 2008, Toronto, Canada, as a poster presentation, entitled: "Effect of Pressure on Cement-Ceramic Adhesion in Microtensile Bond Tests". 


\section{Tables}

Table 1 Composition and manufacturer's recommendation of the resin cement

Table 2 Mean and standard deviations (SD) of the bond strength data (MPa) of the studied groups, number $\left(\mathrm{N}^{\circ}\right)$ of tested specimens (sp) per group and incidence of cohesive failure after the microtensile test.

\section{Figures}

Figure 1 Means and standard deviation of the microtensile bond strength data regardless of the five seating forces conditions applied in the cementation procedure.

Figure 2 SEM images of the cement thicknesses at the interface between ceramic and resin composite cementation surfaces after application of seating forces in each group a) $\mathrm{G}_{10}$, b) $\mathrm{G}_{50}$, c) $\mathrm{G}_{100}$, d) $\mathrm{G}_{500}$, and e) $\mathrm{G}_{750}$. 


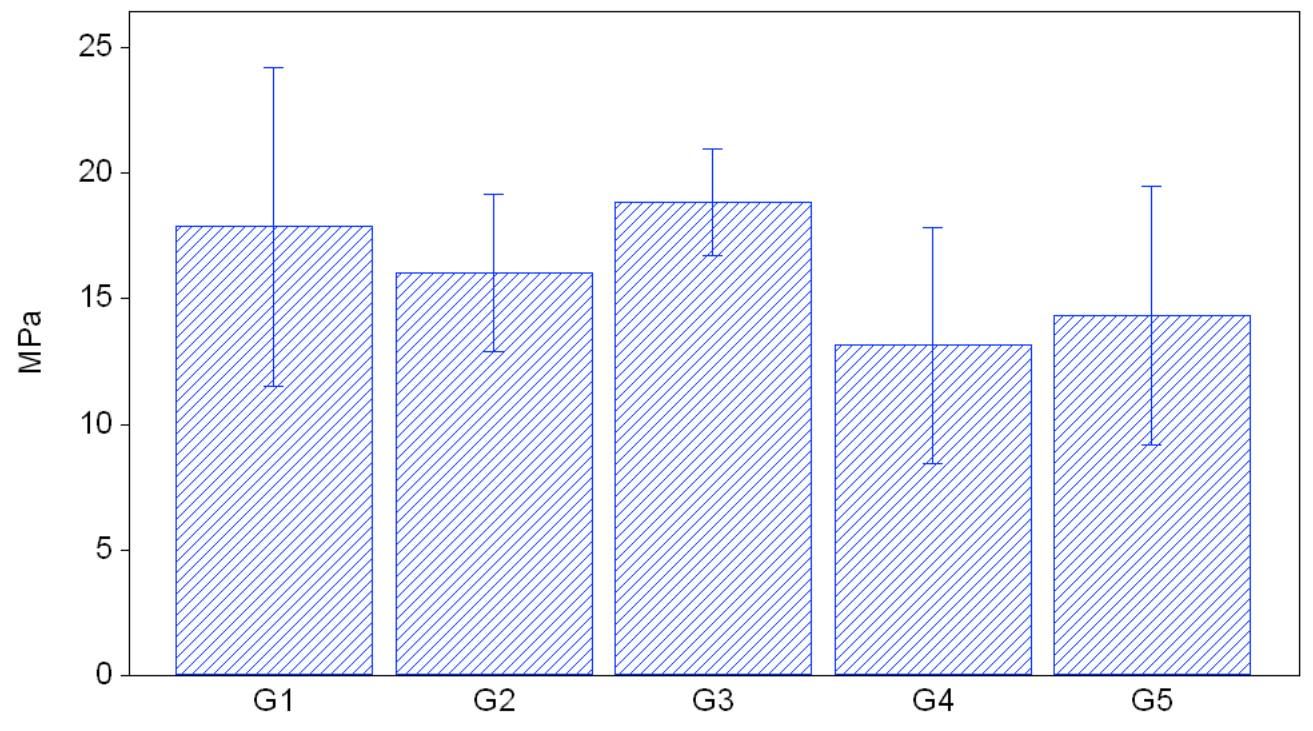

Figure 1 - Means and standard deviation of the microtensile bond strength data regardless of the five seating forces conditions applied in the cementation procedure. 

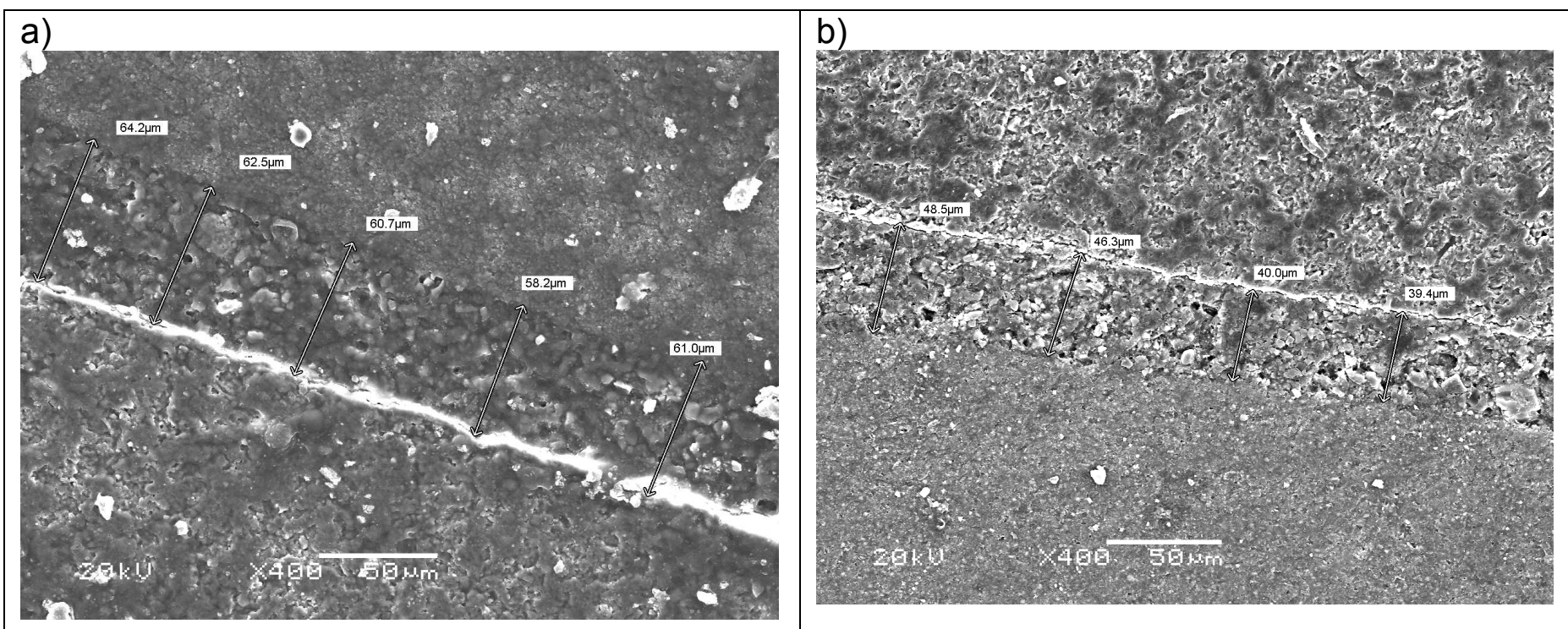

c)

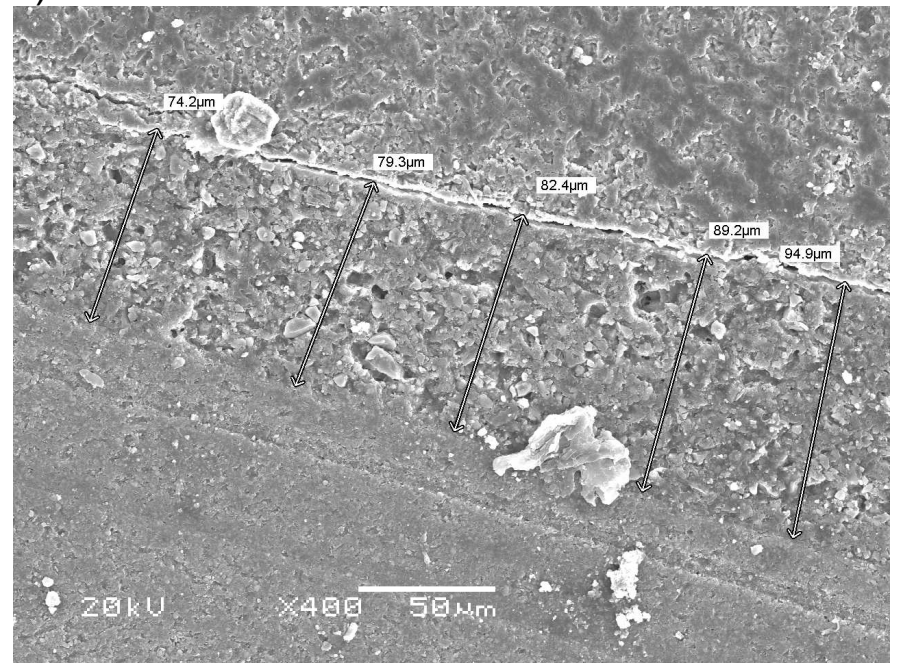

d)

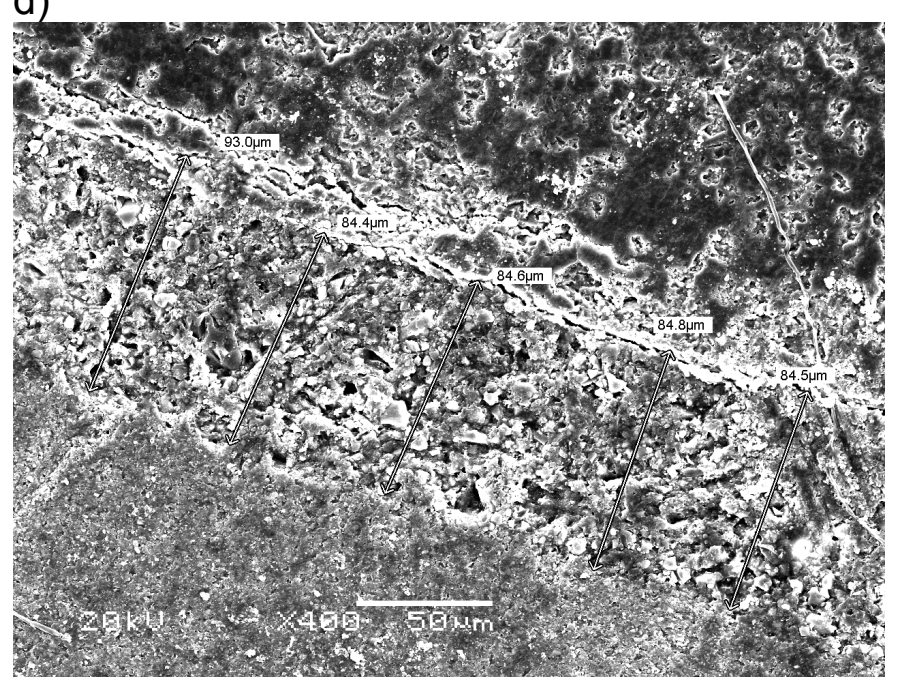

e)

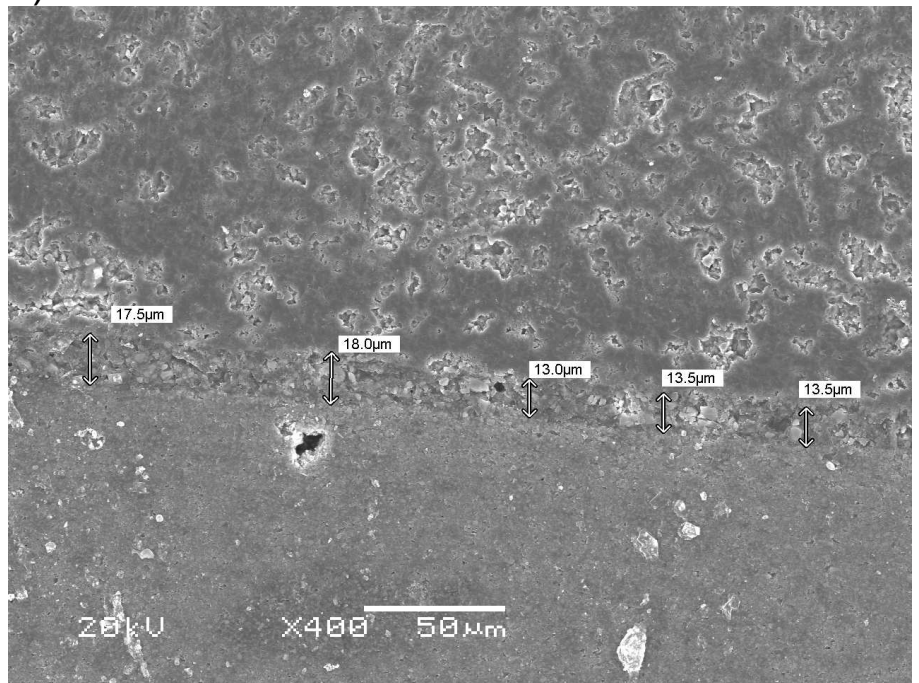


Figure 2 - SEM images of the cement thicknesses at the interface between ceramic and resin composite cementation surfaces after application of seating forces in each group a) $G_{10}$, b) $G_{50}$, c) $G_{100}$, d) $G_{500}$, and e) $G_{750}$. 